\title{
Anticoagulants for Stroke Prevention in Atrial Fibrillation in Elderly Patients
}

\author{
Andreas Schäfer $^{1}$ • Ulrike Flierl ${ }^{1}$. Dominik Berliner ${ }^{1}$. Johann Bauersachs ${ }^{1}$
}

Published online: 29 April 2020

(C) The Author(s) 2020

\begin{abstract}
Ischaemic stroke and systemic embolism are the major potentially preventable complications of atrial fibrillation (AF) leading to severe morbidity and mortality. Anticoagulation using vitamin K antagonists (VKA) or non-vitamin K oral anticoagulants (NOACs) is mandatory for stroke prevention in AF. Following approval of the four NOACs dabigatran, rivaroxaban, apixaban, and edoxaban, the use of VKA is declining steadily. Increasing age with thresholds of 65 and 75 years is a strong risk factor when determining annual stroke risk in AF patients. Current recommendations such as the "2016 Guidelines for the management of atrial fibrillation" of the European Society of Cardiology and the "2019 AHA/ACC/HRS Focused Update" by the American College of Cardiology, the American Heart Association, and the Heart Rhythm Society strengthen the importance of anticoagulation and detection of bleeding risks, of which older age is an important one. While patients aged $\geq 75$ years are usually underrepresented in randomised clinical trials, they represent almost $40 \%$ of the trial populations in the large NOAC approval studies. Therefore, a sufficient amount of data is available to assess the efficacy and safety for this patient cohort in that specific indication. In this article, the evidence for stroke prevention in AF using either VKA or NOACs is summarised with a special focus on efficacy compared to bleeding risk in patients aged $\geq 75$ years. Specifically, we used a model of increased weighing of intracranial bleeding to illustrate the potential benefit of NOACs over VKA in the elderly population. In brief, there are at least two tested strategies with apixaban and edoxaban which even confer an additional clinical net benefit compared with VKA. Furthermore, elderly subgroups of trials for combined antithrombotic treatment following percutaneous coronary interventions in anticoagulated patients are analysed.
\end{abstract}

Keywords Anticoagulation $\cdot$ VKA $\cdot$ NOAC $\cdot$ Elderly patients $\cdot$ Atrial fibrillation

\section{Indication for Stroke Prevention in Elderly Patients}

Ischaemic or embolic strokes are the major disabling complications in patients with atrial fibrillation (AF). Oral anticoagulation $(\mathrm{OAC})$ can prevent most of these events and is, therefore, widely used for stroke prevention in AF. Excluding patients with very low stroke risks, the superiority of OAC compared with non-treatment is overwhelming and, based on current European Society of Cardiology (ESC) "2016 Guidelines for the management of atrial fibrillation" and the "2019 AHA/ACC/HRS Focused Update of the 2014

Andreas Schäfer

schaefer.andreas@mh-hannover.de

1 Department of Cardiology and Angiology, Hannover Medical School, Carl-Neuberg-Str. 1, D-30659 Hannover, Germany
Guideline for the Management of Patients With Atrial Fibrillation" by the American College of Cardiology, the American Heart Association, and the Heart Rhythm Society, should be used in stroke prevention in AF [1, 2]. Furthermore, the European Heart Rhythm Association (EHRA) "2018 EHRA Practical Guide on the use of non-vitamin K antagonist oral anticoagulants in patients with atrial fibrillation" elucidates the advantage of non-vitamin $\mathrm{K}$ oral anticoagulants (NOACs) compared with vitamin K antagonists (VKA) [3]. Previously, a potential benefit of certain NOACs compared with VKA has been described in a meta-analysis including differing indications for anticoagulation [4]. This article will focus in detail on patients $\geq 75$ years of age treated for stroke prevention in AF. This threshold alone indicates higher embolic as well as increased bleeding risk when using contemporary scoring tools $[5,6]$.

In principle, guidelines recommend stroke prevention in $\mathrm{AF}$ using $\mathrm{OAC}$ in all patients with $\mathrm{CHA}_{2} \mathrm{DS}_{2}$-VASc score $\geq$ 
2 in men and $\geq 3$ in women. Since age $\geq 75$ years gives 2 score points and female sex 1 score point, all patients $\geq 75$ years of age are recommended to receive OAC with a class Ia recommendation irrespective of the presence or absence of additional risk factors [1,2]. While previous meta-analyses focussed on elderly patients in phase II and III trials in AF and venous thromboembolism [4, 7], the current manuscript focuses on patients $\geq 75$ years of age with a specific consideration of intracranial bleeding-related disability and on contemporary data from trials combining OAC with antiplatelet agents following coronary interventions in anticoagulated $\mathrm{AF}$ patients.

\section{Anticoagulation or Antiplatelet Therapy for Stroke Prevention in Atrial Fibrillation in Elderly Patients}

Antiplatelet therapy using acetylsalicylic acid had been a low level recommendation in $\mathrm{AF}$ patients with $\mathrm{CHA}_{2} \mathrm{DS}_{2}$-VASc score $=1$ in previous guidelines, but no longer in the current European or American guidelines [1, 2]. In the European guidelines, it is clearly stated that "antiplatelet monotherapy is not recommended for stroke prevention in AF patients, regardless of stroke risk". In the past, acetylsalicylic acid had been considered as a less harmful option in patients deemed not suitable for OAC due to higher bleeding complications especially in elderly patients. However, in primary prevention trials for cardiovascular disease, age $\geq 70$ years was associated with significantly increased bleeding rates on acetylsalicylic acid compared with younger individuals $[8,9]$. In the Oxford Vascular Study performed in patients with clinically evident atherosclerosis, an increase of major bleedings on acetylsalicylic acid to an annual rate of $2 \%$ in patients aged $75-84$ years and of $4 \%$ in patients above 84 years had been observed; life-threatening or fatal bleedings ranged between 1.0 and $2.5 \%$ annually [10]. The findings regarding acetylsalicylic acid are reproducible in several trials with patients $\geq 75$ years of age; similarly the rate of major bleeds was $5.2 \% / y e a r$ in the recent RE-SPECT ESUS trial [11]. In the Birmingham Atrial Fibrillation Treatment of the Aged Study, patients $\geq 75$ years of age on acetylsalicylic acid did not show a lower rate of major bleedings compared with VKA, but VKA was superior to acetylsalicylic acid regarding stroke prevention. In this study, even very elderly patients, which are often categorised as frail, had a $50 \%$ risk reduction for embolic/ischaemic events on VKA with a similar bleeding risk as on acetylsalicylic acid [12]. However, it has to be considered that VKA treatment in this trial was well controlled with time in therapeutic range of $67 \%$. In the AVERROES trial comparing acetylsalicylic acid and the NOAC apixaban, bleeding rates in elderly AF patients were similarly increased as in the Oxford Vascular Study when treated with acetylsalicylic acid as monotherapy indicating that the observed bleeding rates were representative for this patient population. Of note, when patients were above 85 years, annual rates for stroke or systemic embolism increased to $6.5 \%$, for major bleedings to $4.7 \%$, and for intracranial haemorrhage to $2.9 \%$ on acetylsalicylic acid, but anticoagulation with apixaban showed significantly lower rates of stroke or systemic embolism with safety comparable to acetylsalicylic acid [13].

The four randomised controlled trials evaluating NOACs compared with VKA for stroke prevention in AF consistently showed an annual major bleeding rate of $4.4-5.2 \%$ on VKA in AF patients $\geq 75$ years of age (Table 1) [14-17]. When balancing the rates of stroke or systemic embolism on VKA to that of intracranial haemorrhage, the strongest clinical net benefit is in patients at greatest risk, e.g. those above 85 years of age [18]. In general, while the bleeding rate in elderly patients might be lower on acetylsalicylic acid than on VKA, there is still a much stronger efficacy with VKA. Considering the clinical net benefit, acetylsalicylic acid is not an option for stroke prevention in $\mathrm{AF}$ in patients $\geq 75$ years of age because of comparable harm but much lower efficacy. Therefore, the contraindication from current guidelines regarding antiplatelet monotherapy for stroke prevention in $\mathrm{AF}$ also applies for elderly patients, irrespective whether a population above 75 or above 85 years of age is considered. The combination of NOACs and platelet inhibitors in elderly patients was beyond the scope of this review and has recently been reviewed [19].

\section{NOACs for Stroke Prevention in AF in the Elderly: Approval Trials}

As the four different studies evaluating NOACs compared with VKA for stroke prevention in AF are different in inclusion and exclusion criteria as well as in underlying stroke risk by $\mathrm{CHADS}_{2}$ score, the 4 NOACs cannot be compared directly, but an impression on clinical net benefit consisting of the trials individual primary efficacy (usually stroke or systemic embolism) and safety (major bleedings according to study definition) endpoints can be given. The different dosing regimens, bleeding definitions, and proportion of elderly within the trial as well as the effect on primary endpoints in the overall populations are summarised in Table 1, while the main text refers to relative increase and decrease of events in the studies.

\section{Dabigatran in RE-LY}

The RE-LY trial compared the direct thrombin-inhibitor dabigatran to warfarin. In the overall trial, dabigatran at $2 * 150 \mathrm{mg}$ /day reduced the rate of stroke or systemic embolism by $34 \%$ with a similar rate of major bleeds; dabigatran at $2 * 110 \mathrm{mg} /$ day showed a similar rate of stroke or systemic 


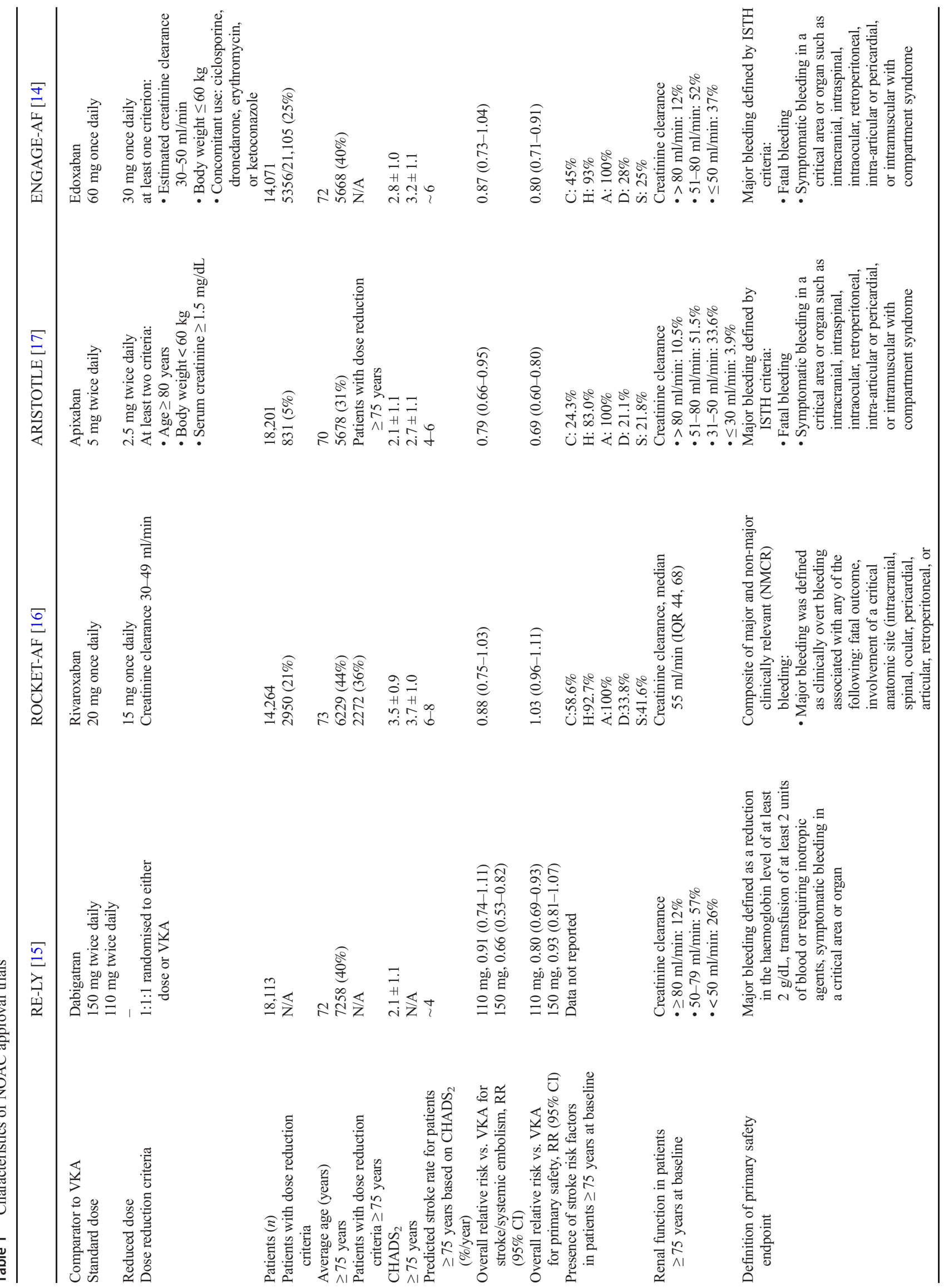




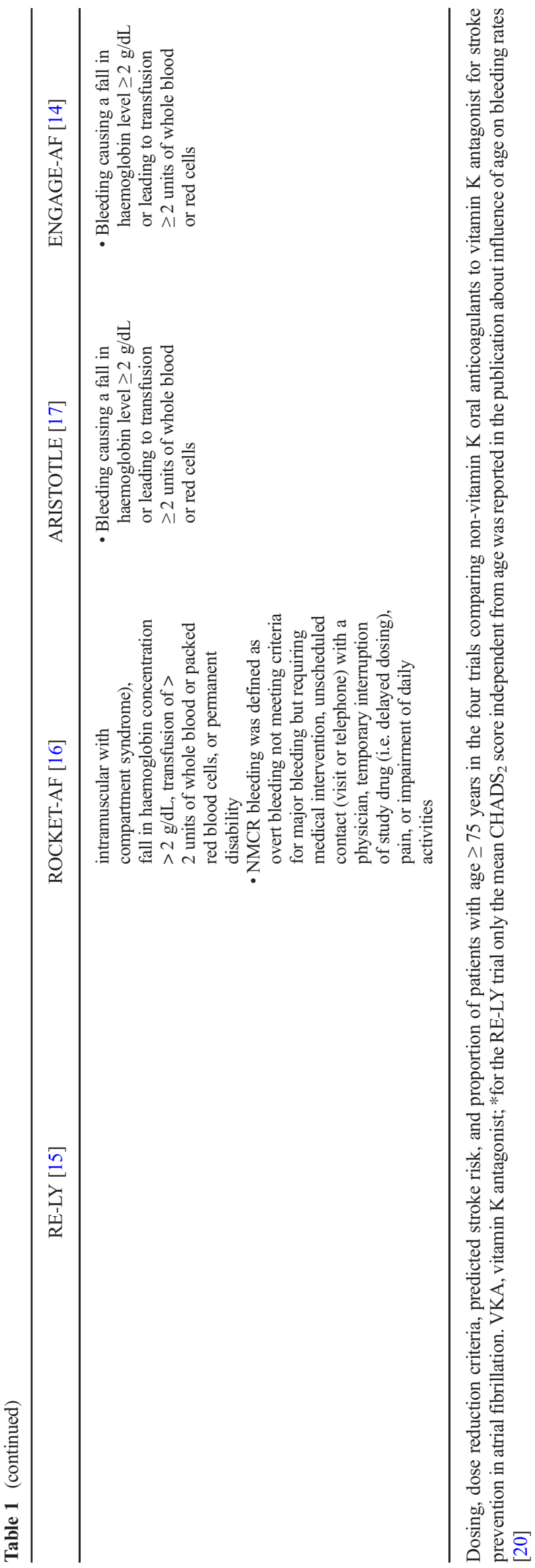

embolism but reduced the rate of major bleeding by $20 \%$ compared with VKA [15]. As there was no clinical dose reduction criteria and both doses had been randomised to VKA in a 1:1:1 fashion, age did not influence dabigatran dosing. While dabigatran $2 * 150 \mathrm{mg}$ /day reduced stroke or systemic embolism in the elderly by $33 \%$, major bleeding was increased by $18 \%$. While the bleeding increase did not reach statistical significance, the European Medicines Agency restrained the approval to patients $<80$ years of age. On dabigatran $2 * 110 \mathrm{mg} /$ day, the reduction of stroke and systemic embolism by $12 \%$ was not significant, but the risk of bleeding was similar to VKA (Figs. 1 and 2 top). Overall, in patients $\geq 75$ years of age, the combined risk of stroke or systemic embolism and major bleeding was similar between VKA and both dosages of dabigatran [20]. While there was a clinical net benefit for both doses of dabigatran in the overall RELY trial, this conclusion cannot be extrapolated to patients $\geq$ 75 years of age. For these patients, the increase in major bleedings counteracts the benefit of lower embolic rates.

\section{Rivaroxaban in ROCKET-AF}

The ROCKET-AF trial compared the factor Xa-inhibitor rivaroxaban to warfarin. In the overall trial, rivaroxaban was similarly effective for prevention of stroke or systemic embolism with a similar rate of major bleeds [16]. In ROCKET-AF $44 \%$ of patients were $\geq 75$ years of age [21]. As the dose of rivaroxaban was only reduced in patients with impaired renal function, age did not directly influence rivaroxaban dosing. In the elderly, rivaroxaban was at least as effective preventing stroke or systemic embolism and similarly safe regarding major bleeding (Figs. 1 and 2 middle). In line with the overall ROCKET-AF trial, there was no clinical net benefit for patients $\geq 75$ years of age for rivaroxaban over VKA.

\section{Apixaban in ARISTOTLE}

The ARISTOTLE trial compared the factor Xa-inhibitor apixaban to warfarin. In the overall trial, apixaban compared with VKA reduced the rate of stroke or systemic embolism by $21 \%$ and the rate of major bleeding by $31 \%$ [17]. In ARISTOTLE $31 \%$ of patients were $\geq 75$ years of age [22]. Age directly influenced apixaban dosing as age $\geq 80$ years was one of three dose reduction criteria, of which two had to be present to reduce the daily dose by $50 \%$. While only $5 \%$ of the total trial population fulfilled at least two dose reduction criteria, $95 \%$ of those patients were $\geq$ 75 years of age. In the elderly, apixaban reduced stroke or systemic embolism by $29 \%$ and major bleeding by $36 \%$ (Figs. 1 and 2 middle). Similar to the overall ARISTOTLE trial, the clinical net benefit for patients $\geq 75$ years of age was in favour of apixaban by reducing both embolic as well as major bleeding events. 


\section{Edoxaban in ENGAGE-AF}

The ENGAGE-AF trial compared the factor Xa-inhibitor edoxaban to warfarin. This article will only focus on the higher tested dose of edoxaban (full dose of $60 \mathrm{mg}$ with clinical dose reduction criteria to $30 \mathrm{mg}$ ), because another lower dosing regimen of $30 / 15 \mathrm{mg}$ edoxaban had been tested in another 7034 patients in an original 1:1:1 randomisation, but was not approved for stroke prevention in AF. In the overall trial, edoxaban was equally effective in preventing stroke or systemic embolism (non-significant reduction by $13 \%$ ) and reduced major bleeding by $20 \%$ compared with VKA [14]. In ENGAGE-AF $40 \%$ of patients were $\geq 75$ years of age [23]. Age did not directly influence edoxaban dosing. While 25\% of the total trial population fulfilled dose reduction criteria, $65 \%$ of those patients were $\geq 75$ years of age. In the elderly, edoxaban was at least as effective preventing stroke or systemic embolism and reduced major bleeding by $17 \%$ (Figs. 1 and 2 bottom). Similar to the overall ENGAGE-AF trial, the clinical net benefit for patients $\geq 75$ years of age was in favour of edoxaban driven primarily by reducing major bleeding.

In summary, it seems reasonable to use NOACs for elderly patients with AF instead of VKA. Similar to the general AF populations investigated in the trials, all four NOACs are at least as effective as VKA. There appears to be some additional benefit for apixaban and the higher dose of dabigatran regarding stroke prevention. However, on the bleeding side, the higher dose of dabigatran is not recommended in patients $\geq$ 80 years of age by several authorities. Overall, apixaban and edoxaban had a lower risk of major bleeding in elderly patients as in the general study populations.

When comparing NOACs in general to VKA, the major advantage of NOACs is the $52 \%$ risk reduction for intracranial haemorrhage, and the major downside is the $25 \%$ increase in gastrointestinal bleedings. However, in all four NOAC approval studies, there was only an excess of 160 gastrointestinal bleedings for 221 intracranial haemorrhages prevented on NOAC versus VKA [24]. Nevertheless, both bleeding sites need to be addressed in the elderly population.

\section{Gastrointestinal Bleedings on NOACs in the Elderly}

In patients $\geq 75$ years of age, gastrointestinal bleeding rates are increased on some NOACs compared with VKA (dabigatran a

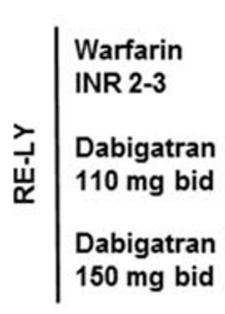

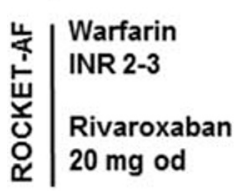

\begin{tabular}{l|l} 
W & Warfarin \\
INR 2-3 & IN \\
$\stackrel{5}{\circ}$ & Apixaban \\
$\frac{\mathscr{Q}}{\alpha}$ & $5 \mathrm{mg}$ bid
\end{tabular}

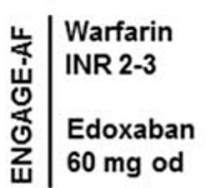
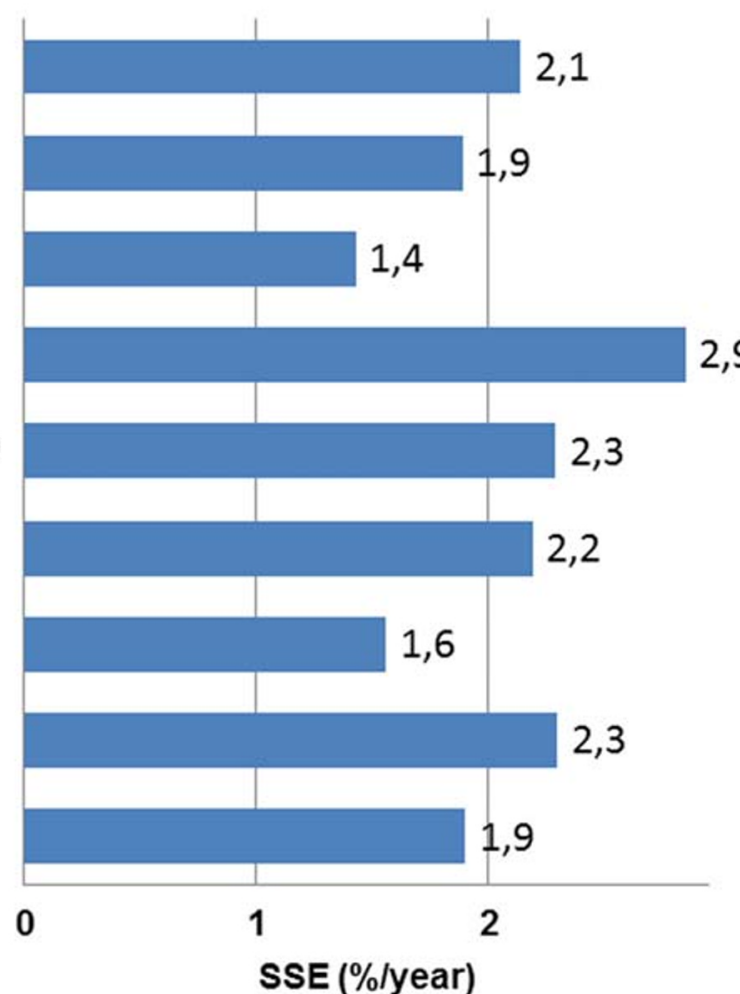

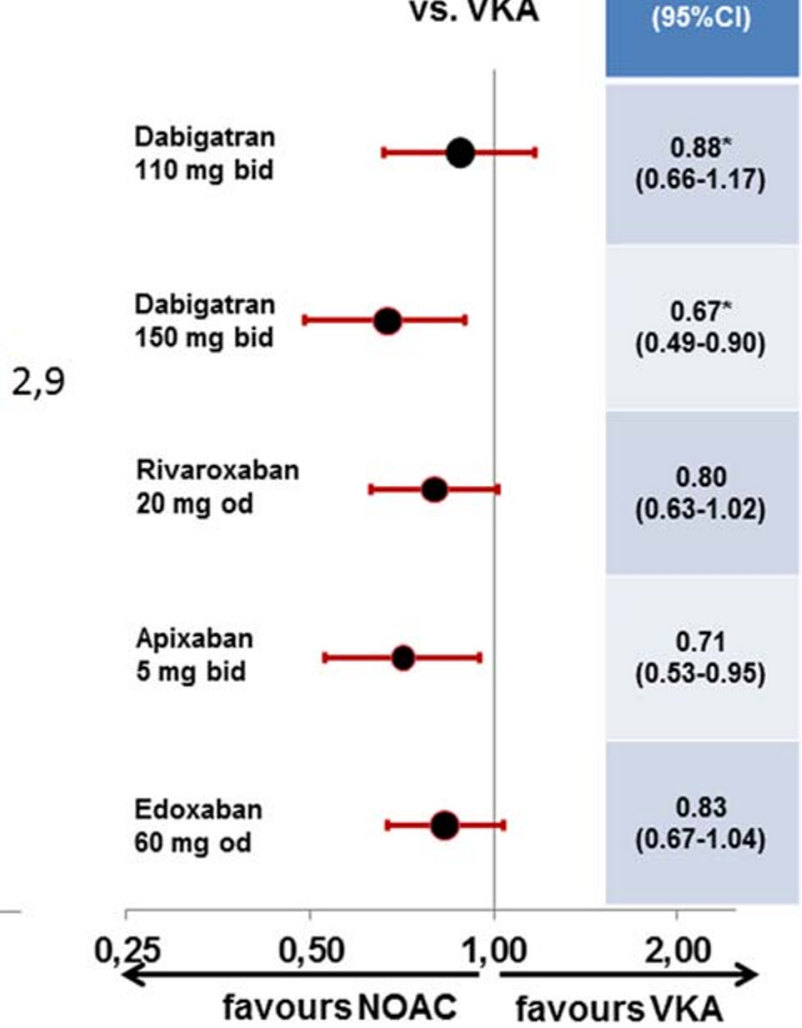

b

Fig. 1 Event rates (a) and hazard ratios (or relative risk for dabigatran) (b) for stroke or systemic embolism in patients $\geq 75$ years of age in the four trials comparing non-vitamin $\mathrm{K}$ oral anticoagulants to vitamin $\mathrm{K}$ antagonist for stroke prevention in atrial fibrillation. HR, hazard ratio; NOAC,

non-vitamin K oral anticoagulants; RR, relative risk; SSE, stroke or systemic embolism; VKA, vitamin K antagonist. Definition of major bleeding according to study criteria as well as dosing regimens is given for all studies in Table 1 
$110 \mathrm{mg}+38 \%$, dabigatran $150 \mathrm{mg}+75 \%$, rivaroxaban + $69 \%$, edoxaban $+29 \%)[20,21,23]$. The analysis of patients aged $\geq 75$ years on apixaban does not state gastrointestinal bleeding rates [22], but the submission document to German health authorities shows an equal risk of major gastrointestinal bleedings for patients $\geq 75$ years of age for apixaban compared with VKA in the approval study [25](Fig. 3). However, it is difficult to attribute the risk solely to the specific NOAC in the trial. The risk for gastrointestinal bleeding may also depend on co-administration of platelet inhibitors (increase of bleeding) and proton-pump inhibitors (decrease of bleeding). In RE-LY, $40 \%$ of all patients received concomitant acetylsalicylic acid, and $18 \%$ received proton-pump inhibitors or a histamine 2 receptor antagonist [20]. In ROCKET-AF, acetylsalicylic acid was used at randomisation by $57 \%$ of patients and $14 \%$ received proton-pump inhibitors. In ARISTOTLE, similarly $18 \%$ received gastric antacid drugs, but acetylsalicylic acid was only used in about $20 \%$ of patients throughout the trial [26]. In ENGAGE-AF, the ratio of patients receiving acetylsalicylic acid at randomisation was similar in patients aged $\geq 75$ years with $29 \%$ as in the overall trial population; dedicated information on proton-pump inhibitors has not been mentioned in the publications [23]. Thereby, the lower rate of acetylsalicylic acid users in ARISTOTLE might have positively influenced the lower gastrointestinal bleeding signal. Nevertheless, the observation of lower gastrointestinal bleedings on apixaban compared with other NOACs is reported from several US and German post market healthcare databases $[27,28]$. Of note, in a randomised placebo-controlled trial for low-dose anticoagulation in cardiovascular disease routine use of proton-pump inhibitors in patients receiving low-dose anticoagulation and/or aspirin, pantoprazole significantly reduced bleeding of gastroduodenal lesions [29].

In summary, it might be feasible to combine oral anticoagulation in particular in elderly patients with routine PPI treatment to prevent gastrointestinal bleeding and to refrain from concomitant antiplatelet therapy whenever possible.

\section{Intracranial Bleedings on NOACs in the Elderly}

When assessing intracranial haemorrhages in patients $\geq$ 75 years of age, the rates with all NOACs are lower than in a

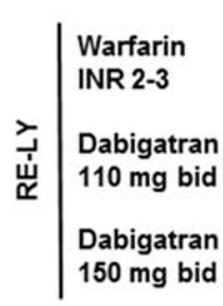

\section{岁 Warfarin \begin{tabular}{l|l} 
INR 2-3 & INR \\
L & Rivaroxaban \\
$20 \mathrm{mg}$ od
\end{tabular}}

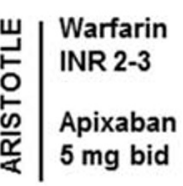

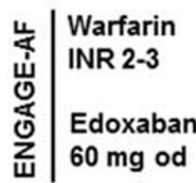

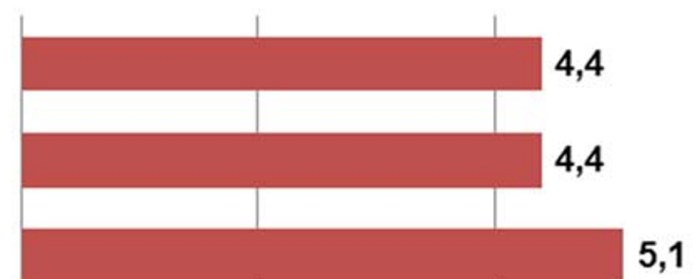

4,4
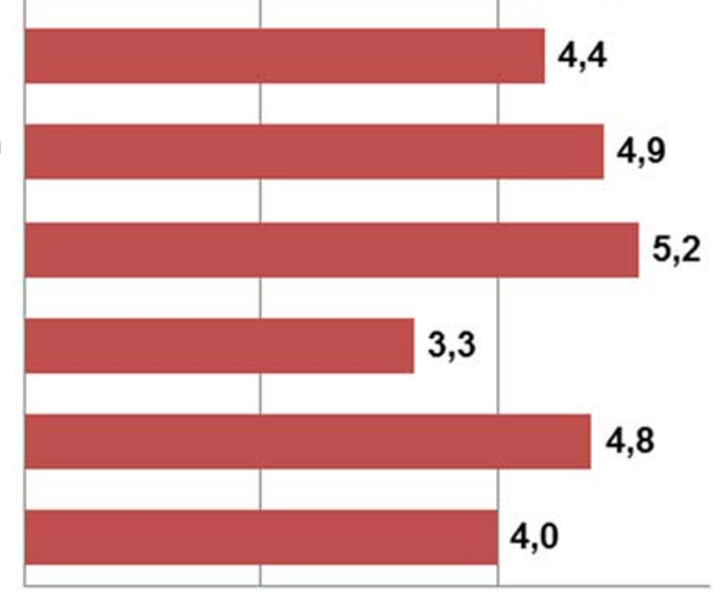

0
2 4 b

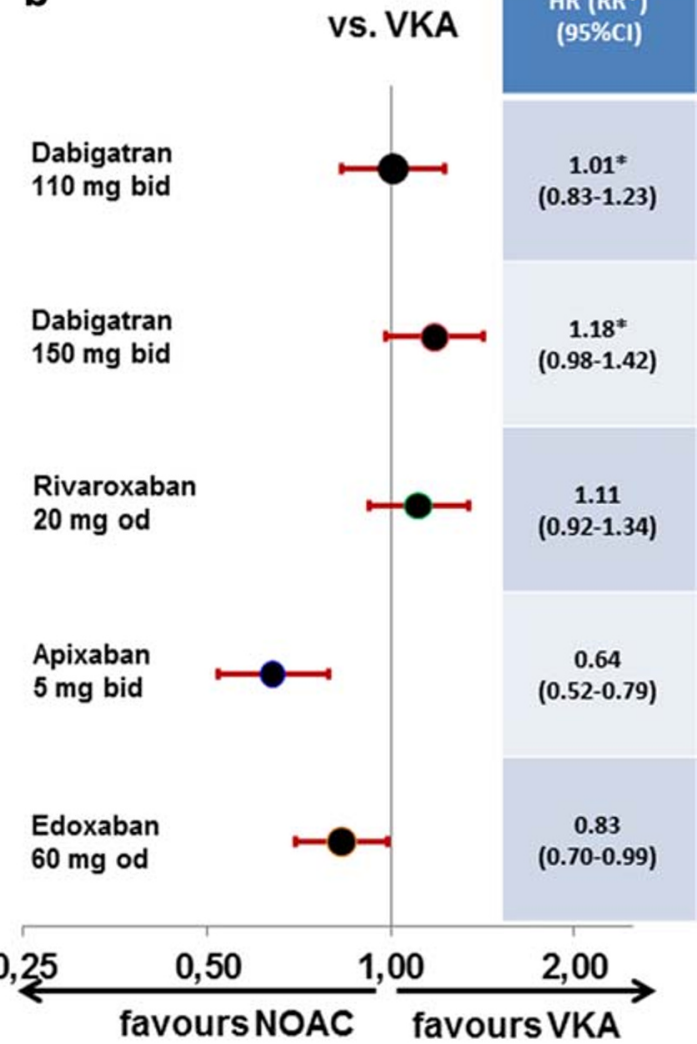

Fig. 2 Event rates (a) and hazard ratios (or relative risk for dabigatran) (b) for major bleedings in patients $\geq 75$ years of age in the four trials comparing non-vitamin $\mathrm{K}$ oral anticoagulants to vitamin $\mathrm{K}$ antagonist for stroke prevention in atrial fibrillation. HR, hazard ratio; NOAC,

non-vitamin K oral anticoagulants; RR, relative risk; SSE, stroke or systemic embolism; VKA, vitamin K antagonist. Definition of major bleeding according to study criteria as well as dosing regimens is given for all studies in Table 1 
their respective matched VKA groups, but the effect appears to be less striking in the ROCKET-AF trial using rivaroxaban (Fig. 4). Previously, in a net clinical benefit analysis from the ATRIA trial [18], a higher factor was attributed to the risk of intracranial haemorrhage due to its higher fatality compared with other major bleedings and stroke or systemic embolism. In their publication, the authors defined the core net clinical benefit of anticoagulation therapy in $\mathrm{AF}$ as the annualised rate of thromboembolic events prevented minus the annualised rate of major bleedings induced, whereby intracranial haemorrhages are multiplied by a weighting factor. The weighting factor reflects the relative impact, in terms of death and disability, of an intracranial haemorrhage while receiving anticoagulation versus experiencing an ischaemic stroke while not receiving anticoagulation. In our analysis, we used the same principle to compare the different NOACs to the former standard of VKA. In their initial analysis, the authors used a weighting factor of 1.5 reflecting outcomes in the ATRIA study cohort [18]. When applying such an analysis for NOACs vs. VKA, one detects the highest and significant benefit in elderly patients compared with VKA on apixaban followed by edoxaban, whereas in elderly patients, rivaroxaban or either dose of dabigatran only provided a slight numerical benefit (Fig. 5). Including specifically intracranial bleeding in balancing risk and benefit in elderly anticoagulated AF patients, the overall impression favouring apixaban and to some extent edoxaban is not changed but indeed strengthened.

\section{NOAC Dose Reduction in the Elderly}

For dabigatran, age had not been a dose reduction criterion in RE-LY [15]. Based on the higher bleeding rates, dabigatran $150 \mathrm{mg}$ is not recommended for patients $\geq 80$ years of age in Europe, and a lower dose should be considered for patients 75-79 years of age. In the USA, no age restriction is recommended.

For rivaroxaban, age had not been a dose reduction criterion in ROCKET-AF [16]. Dose reductions are not recommended for any age and are driven by renal function, which is more often impaired in elderly.

For apixaban, age $\geq 80$ years is one of the factors for dose reductions to $2 * 2.5 \mathrm{mg} / \mathrm{day}$ as recommended from ARISTOTLE [17] if two or more of them are met. Patients on VKA who meet these criteria have higher embolic and bleeding rates than non-affected VKA patients. Patients $\geq$ 75 years not meeting these criteria have a clinical net benefit a

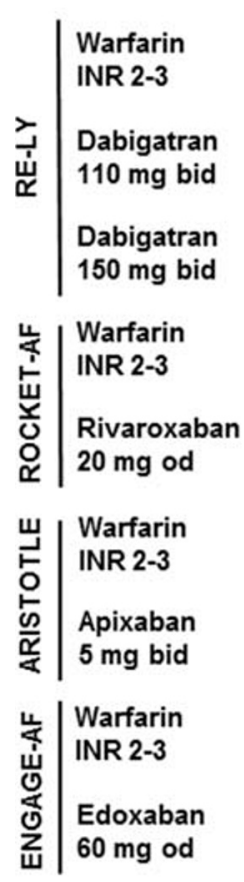

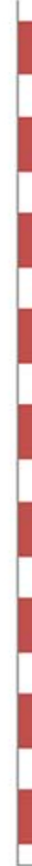

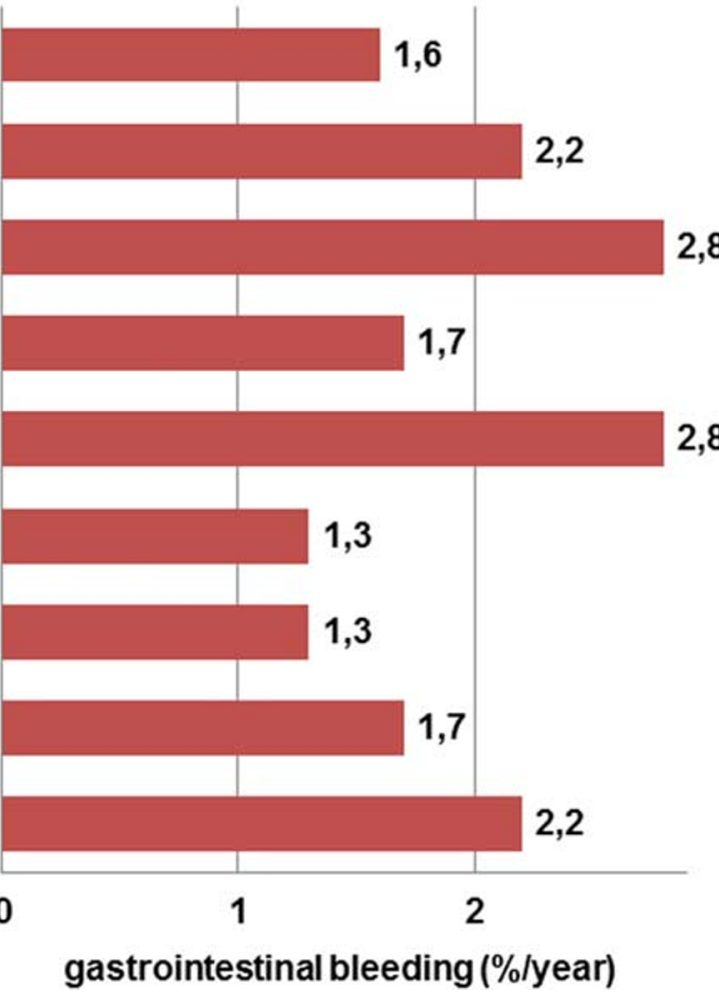

b

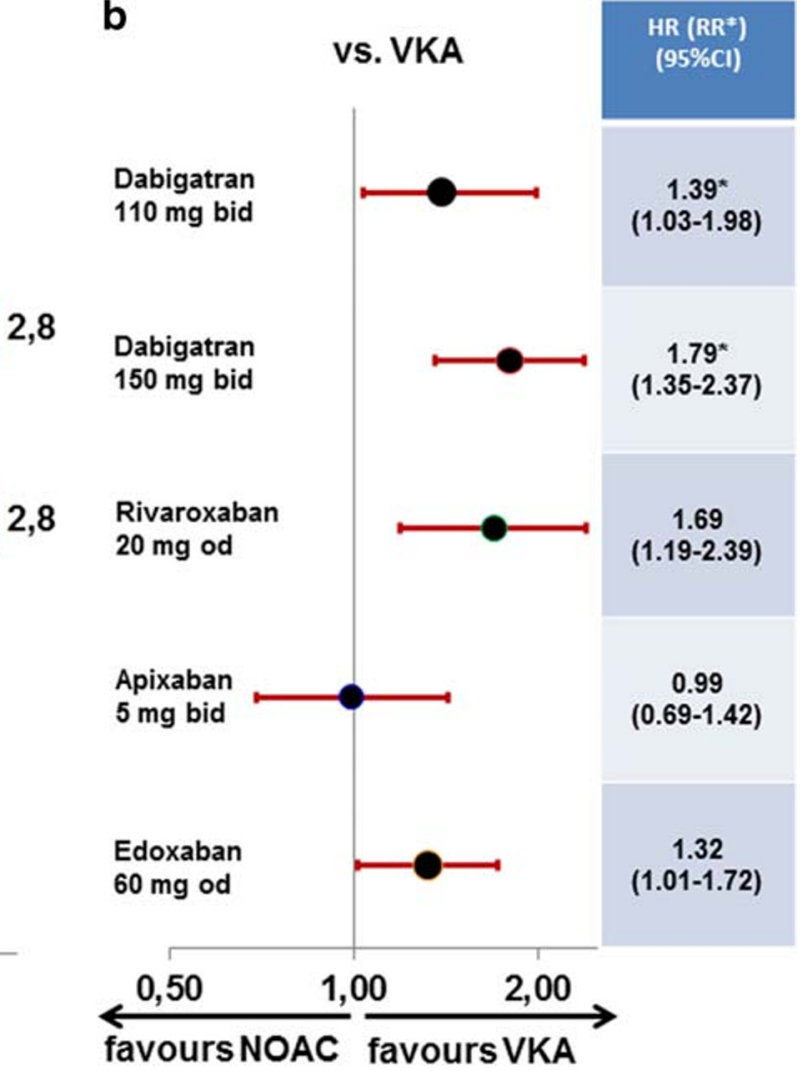

stroke prevention in atrial fibrillation. HR, hazard ratio; NOAC, nonvitamin $\mathrm{K}$ oral anticoagulants; RR, relative risk; VKA, vitamin $\mathrm{K}$ antagonist. Dosing regimens are given for all studies in Table 1

Fig. 3 Event rates (a) and hazard ratios (or relative risk for dabigatran) (b) for gastrointestinal bleeding in patients $\geq 75$ years of age in the four trials comparing non-vitamin $\mathrm{K}$ oral anticoagulants to vitamin $\mathrm{K}$ antagonist for 
compared with VKA similar to younger patients if they are treated with the full $2 * 5 \mathrm{mg} /$ day dose of apixaban. Patients $\geq$ 75 years fulfilling the reduction criteria have a clinical net benefit compared with VKA if they are treated with the reduced $2 * 2.5 \mathrm{mg}$ /day dose of apixaban (Fig. 6 top). Regarding the very elderly patients $\geq 80$ years of age, there was a $30 \%$ clinical net benefit in favour of apixaban compared with VKA based on lower stroke or systemic embolism (1.5\%/year vs. $1.9 \% /$ year) and major bleedings (3.6\%/year vs. $5.4 \% /$ year) [22].

For edoxaban, age per se had not been a dose reduction criterion in ENGAGE-AF [14]. Dose reductions to $1 * 30 \mathrm{mg} /$ day are recommended in clinical practice based on non-agespecific criteria. Patients on VKA who met the study criteria for dose reduction had higher embolic and bleeding rates than patients on VKA without these criteria. Patients $\geq 75$ years receiving full dose $(1 * 60 \mathrm{mg} /$ day) edoxaban and not meeting these criteria had a similar clinical net benefit compared with patients with VKA as younger patients. Patients $\geq 75$ years who fulfilled the reduction criteria and were treated with the reduced $1 * 30 \mathrm{mg}$ /day dose of edoxaban had a clinical net benefit compared with VKA (Fig. 6 bottom). Regarding the very elderly patients $\geq 80$ years of age, there was a $22 \%$ clinical net benefit in favour of edoxaban compared with VKA based on both lower embolic and major bleeding events [23].

In patients with dose reduction criteria, both apixaban and edoxaban demonstrate clinical net benefit. Again, the need for dose reduction does not change the overall interpretation of NOAC data in elderly patients but rather seems to have contributed to the positive profile of the two agents demonstrating best clinical net benefit.

In general, elderly patients with $\mathrm{AF}$ are not threatened or endangered by treatment with NOACs. First, there was no NOAC trial with lower efficacy than VKA; in contrast some strategies were even more effective. Second, in none of the trials did a NOAC cause more intracranial bleeds than VKA. Third, regarding prevention of extracranial major bleedings, there seems to be a difference between NOACs, but selection of the two strategies with clinically driven dose reduction criteria using apixaban and edoxaban. This is clearly visible once the overall clinical net benefit is assessed, irrespective of adding incremental weighting for intracranial bleeds. To prevent the potential downside of gastrointestinal bleedings, concomitant antiplatelet treatment should be avoided and protonpump inhibitors considered in elderly anticoagulated patients. a

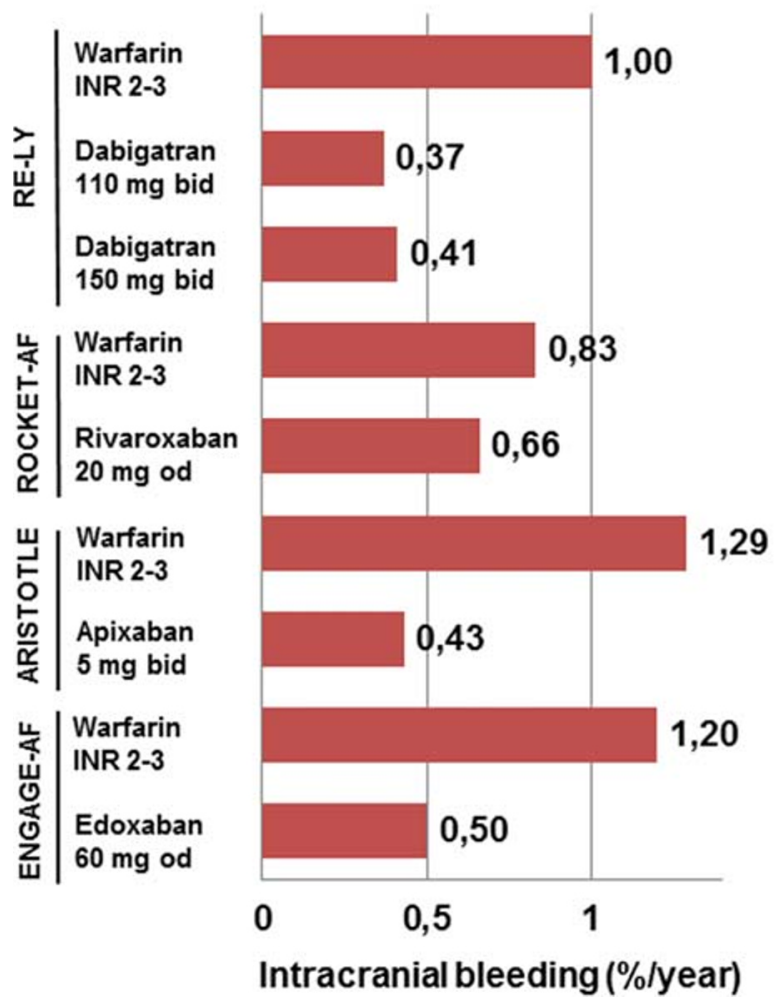

Fig. 4 Event rates (a) and hazard ratios (or relative risk for dabigatran) (b) for intracranial haemorrhage in patients $\geq 75$ years of age in the four trials comparing non-vitamin $\mathrm{K}$ oral anticoagulants to vitamin $\mathrm{K}$ antagonist for b

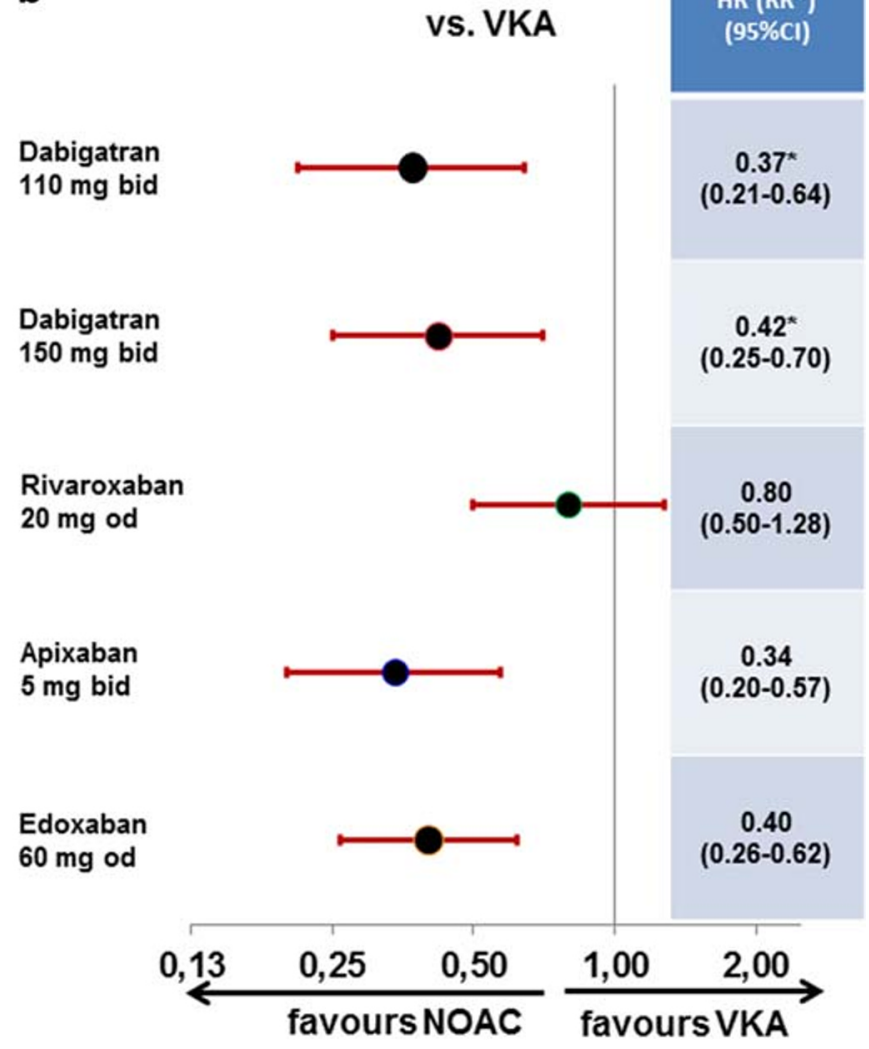

stroke prevention in atrial fibrillation. HR, hazard ratio; NOAC, nonvitamin $\mathrm{K}$ oral anticoagulants; RR, relative risk; VKA, vitamin $\mathrm{K}$ antagonist. Dosing regimens are given for all studies in Table 1 


\section{NOACs in Dual Antithrombotic Therapy Following Coronary Interventions in the Elderly}

When a patient with AF requires PCI with consecutive DAPT, combining ASA + OAC (previously restricted to VKA) + a $\mathrm{P} \mathrm{Y}_{12}$ inhibitor (in combinations predominantly clopidogrel) can increase the risk of bleeding by three- to fourfold compared with OAC alone [30]. Therefore, there had been a quest for alternatives in antithrombotic combination therapies with less bleeding risk. Therefore, two strategies were pursued more recently: first, choosing a NOAC instead of VKA might reduce the bleeding risk already as all four NOAC strategies tested in and approved for stroke prevention in AF use an antithrombotic intensity that is comparable to sub-therapeutic dosing of lowmolecular weight heparins or VKA, and, second, dropping one out of three antithrombotic drugs early after PCI might further reduce bleeding risk, if it is safe regarding prevention of stent thrombosis. VKA and all four NOACs have now been investigated in differing trials combining anticoagulants with antiplatelet treatment aiming for mostly early dropping of acetylsalicylic acid, but some have also applied lower doses of anticoagulants than actually tested and approved for stroke prevention in atrial fibrillation. The only trial randomising for acetylsalicylic acid did so on average $\sim 7$ days after PCI. All trials included much less patients than the approval trials for stroke prevention, so their primary endpoint was not efficacy in terms of stroke (and other ischaemic events) prevention, but rather the reduction of major or clinically relevant non-major bleedings. Thereby, dropping mostly acetylsalicylic acid in the NOAC dual antithrombotic treatment arm will automatically lead to a lower primary bleeding endpoint, but this self-fulfilling prophecy does not mean that patients are equally protected from embolic events. Therefore, we focus first on whether there was a signal on non-equal anti- a

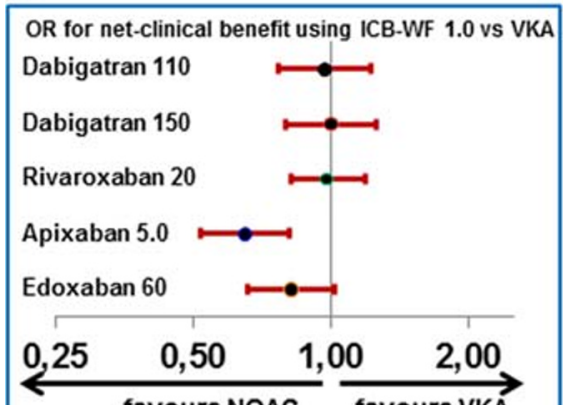

b

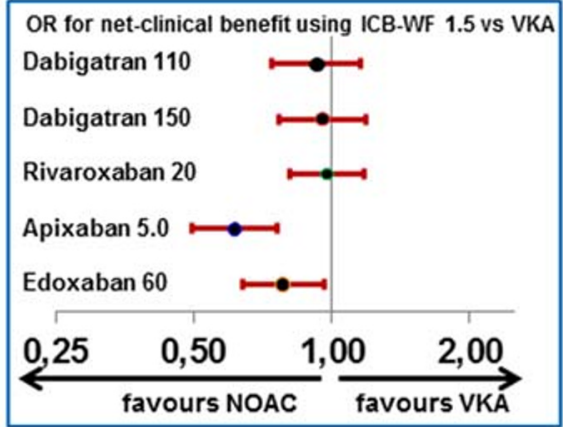

C

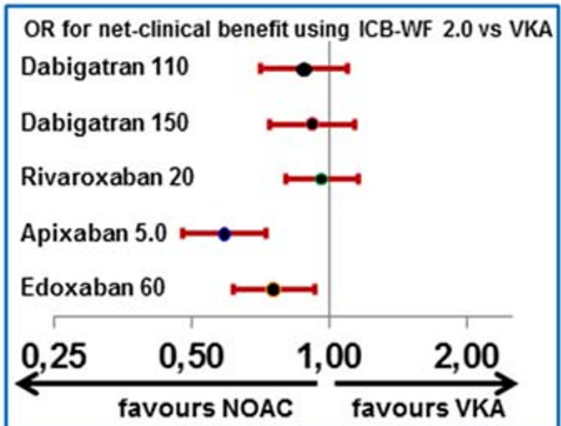

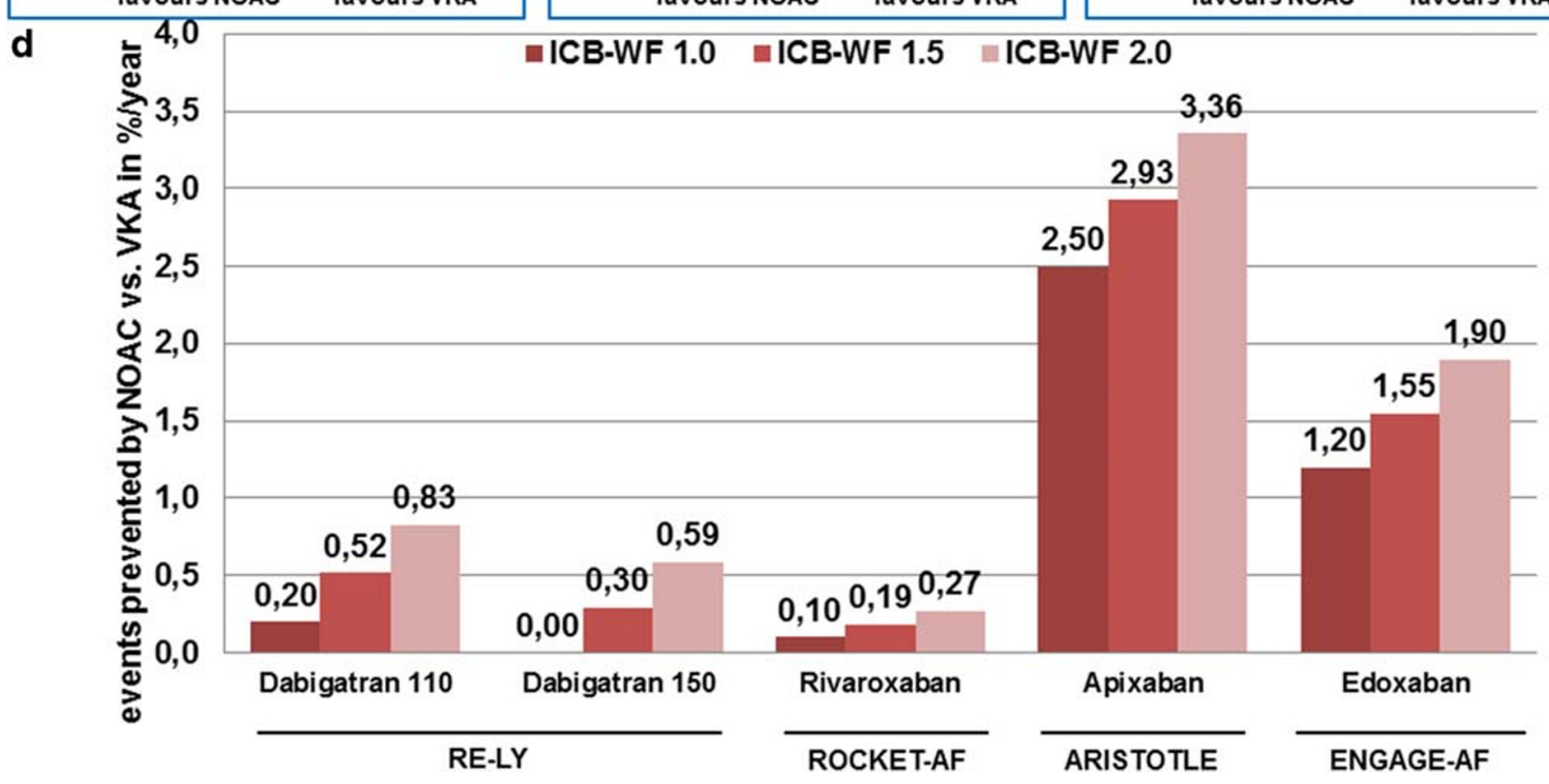

Fig. 5 Net clinical benefit by NOACs compared with VKA in patients $\geq$ 75 years of age in the four NOAC approval trials for stroke prevention in atrial fibrillation based on the event rates for stroke or systemic embolism, major bleeding, and intracranial bleeding (ICB) expressed as odds ratios (OR) calculated based on a weighting factor for ICB, the ICB-WF, set at 1.0 for ICB having similar fatality than other events (a), at 1.5 for ICB

having $50 \%$ higher fatality than other events (b), and at 2.0 for ICB having double the fatality than other events (c) or as number of events prevented/100 patient years of treatment; calculation of the net clinical benefit has been modified according to [18] as explained in the main text. NOAC, non-vitamin K oral anticoagulants; VKA, vitamin K antagonist 
ischaemic protection compared with conventional triple therapy and second whatever data has been reported from elderly patients, which in some studies was $\geq 75$ years and in others $\geq$ 80 years of age. The different trials and definition of the primary endpoint are displayed in Table 2.

The WOEST trial investigated the combination of a vitamin $\mathrm{K}$ antagonist with clopidogrel following PCI in anticoagulated patients (69\% anticoagulated because of AF). In patients $\geq 75$ years of age, the rate of clinically significant bleedings was similarly reduced as in the overall cohort ( $p$ interaction 0.9157 ). In the overall cohort, major adverse cardiovascular events were even reduced on OAC + clopidogrel compared with conventional triple therapy; however, a dedicated analysis regarding elderly patients is not feasible based on the rather low overall study size [31].

The PIONEER-AF trial investigated the combination of the factor Xa-inhibitor rivaroxaban (in a lower than approved dose of
$1 * 15 \mathrm{mg} /$ day during combination antithrombotic treatment or $1 * 10 \mathrm{mg} /$ day in case of impaired renal function) with mostly clopidogrel following PCI in AF patients. In patients $\geq 75$ years of age, the rate of clinically significant bleedings was reduced by $35 \%$; however, major adverse cardiovascular events increased by $69 \%$. A dedicated analysis regarding major bleedings in patients $\geq 75$ years is not yet published; however, their reduction in the overall cohort was $36 \%$. The major concern regarding comorbid patients in PIONEER-AF is that patients with prior stroke or TIA had not been included in the trial and a lower dose of rivaroxaban than recommended and approved for stroke prevention in $\mathrm{AF}$ had been used. The increase in ischaemic events was particularly observed in the elderly [32].

The RE DUAL-PCI trial investigated the combination of the direct thrombin inhibitor dabigatran $(2 * 110 \mathrm{mg} /$ day for all patients $\geq 80$ years of age outside the USA ( $\geq 70$ for Japan)). In patients $\geq 80$ years of age, the rate of clinically significant

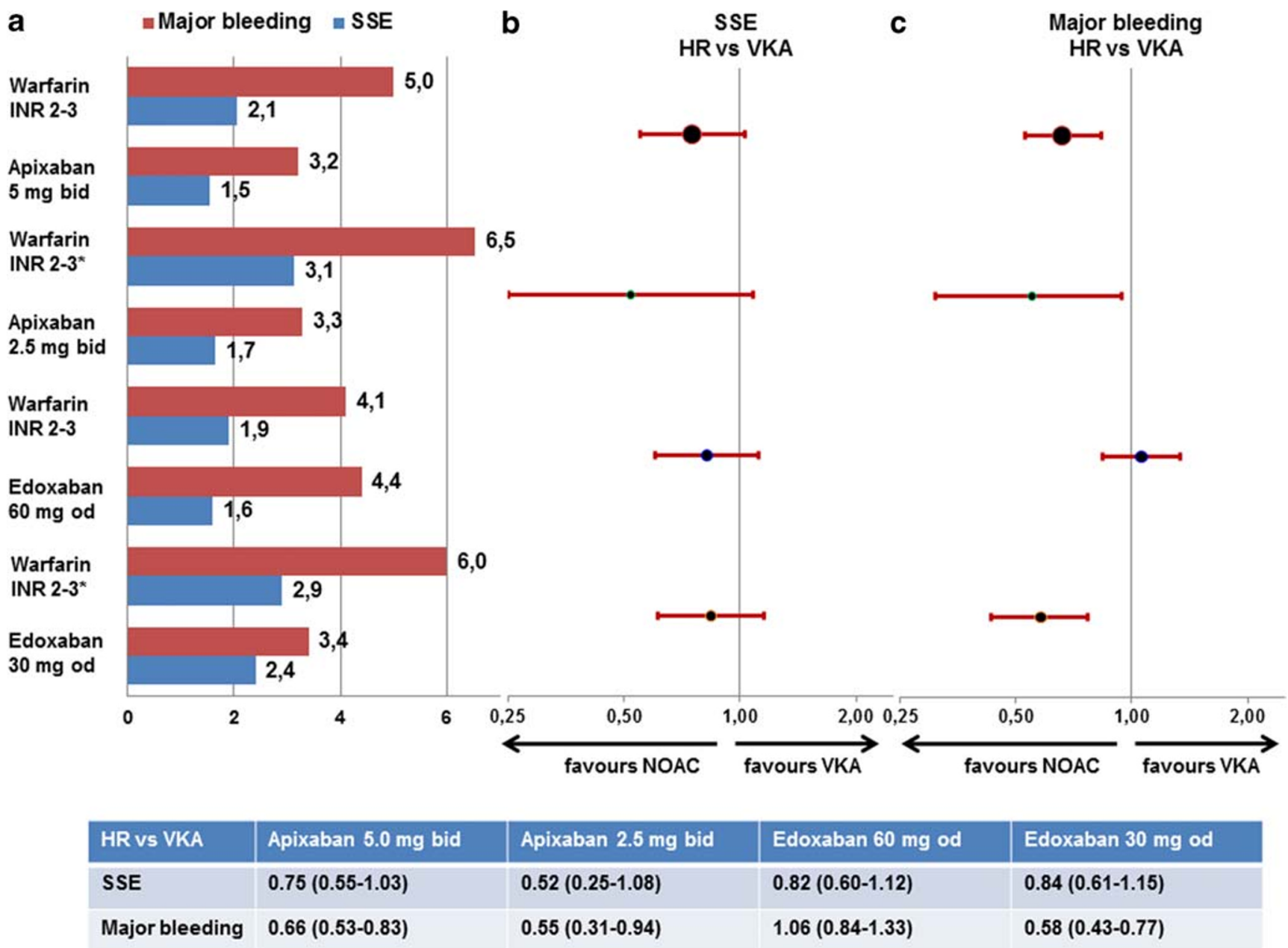

Fig. 6 Event rates (a) and hazard ratios (b, c) for stroke or systemic embolism $(\mathbf{a}, \mathbf{b})$ and major bleedings $(\mathbf{b}, \mathbf{c})$ in patients $\geq 75$ years of age in ARISTOTLE and ENGAGE-AF depending on the presence or absence of study-specific dose reduction criteria. HR, hazard ratio; NOAC, non-vitamin K oral anticoagulants; SSE, stroke or systemic embolism; VKA, vitamin K antagonist. Definition of major bleeding according to study criteria as well as dosing regimens is given for all studies in the main text. * indicates a group of patients qualifying for the study-specific dose reduction criteria who were treated with warfarin 


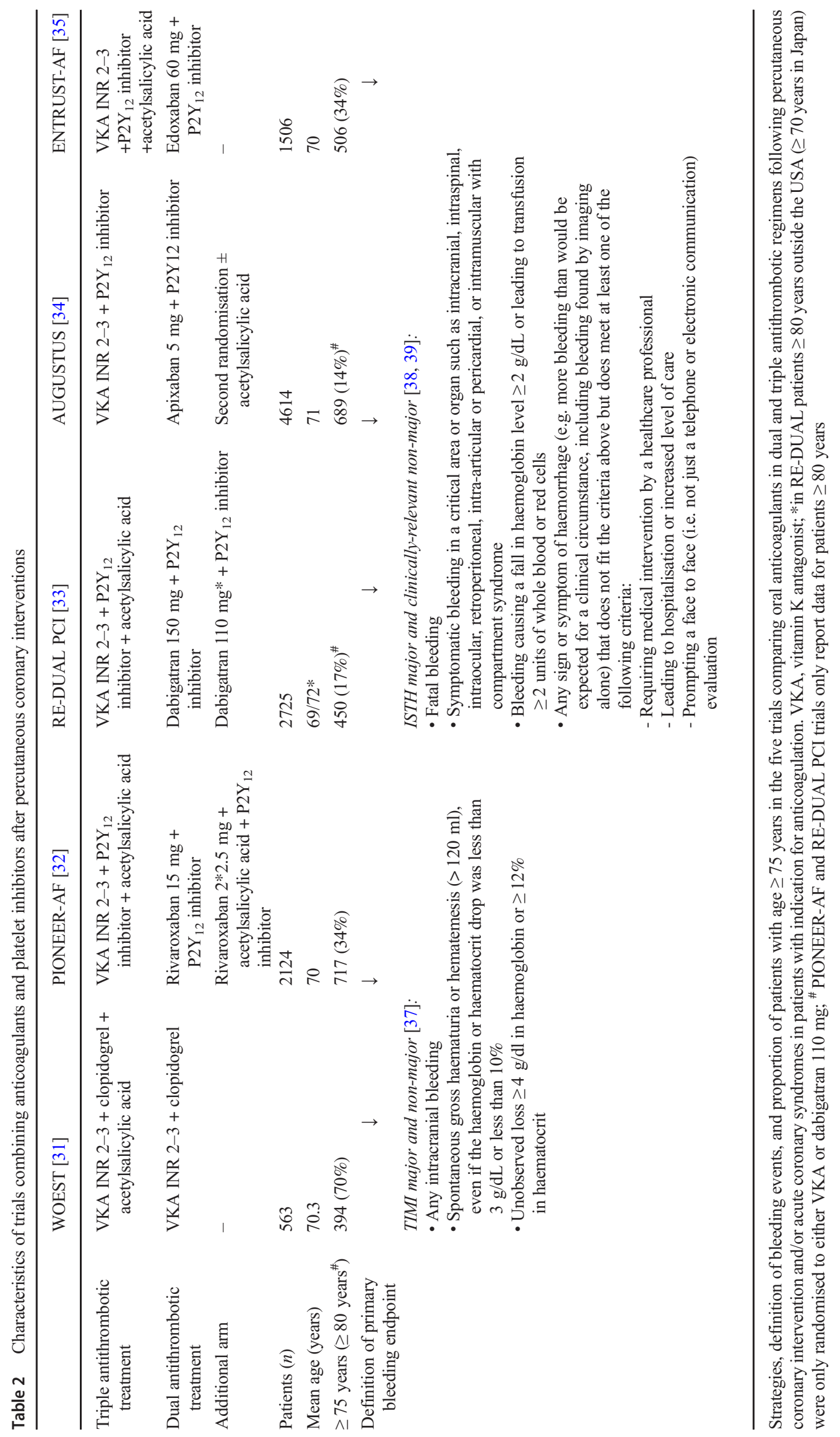


bleedings was reduced by $29 \%$, but the rate of major adverse cardiovascular and revascularisation events increased by $18 \%$. As the trials are underpowered for ischaemic event rates, one has to be careful interpreting non-significant increases in potential harm. A dedicated analysis regarding major bleedings in patients $\geq 80$ years is not yet published. The major concern regarding comorbid patients in RE DUAL-PCI is that only the lower of the approved doses was used as per approval outside the USA, which was associated with an increased rate for stroke, myocardial infarction, and stent thrombosis in the overall cohort [33].

The AUGUSTUS trial investigated the combination of the factor Xa-inhibitor apixaban (in the approved dose of $2 * 5 \mathrm{mg} /$ day or $2 * 2.5 \mathrm{mg} /$ day in case of dose reduction criteria as in ARISTOTLE [17]) with mostly clopidogrel following PCI and/or an acute coronary syndrome in AF. In patients $\geq$ 80 years of age, the rate of clinically relevant bleeding was $15 \%$ lower on apixaban compared with VKA and $83 \%$ higher on acetylsalicylic acid compared with placebo. The rate for all-cause mortality and ischaemic events was $16 \%$ lower on apixaban compared with VKA and $24 \%$ lower on acetylsalicylic acid compared with placebo; however, in the overall trial, this was attributable to the VKA cohort only. Event rates and statistical comparisons for patients $\geq 80$ years of age have not yet been published [34].

The ENTRUST-AF PCI trial investigated the combination of the factor Xa-inhibitor edoxaban (in the approved dose of $1 * 60 \mathrm{mg} /$ day or $1 * 30 \mathrm{mg} /$ day in case of dose reduction criteria as in ENGAGE [14]) with mostly clopidogrel following PCI in AF. In patients $\geq 75$ years of age, the rate of clinically relevant bleeding was $17 \%$ lower on edoxaban compared with VKA, other event rates and statistical comparisons for patients $\geq 75$ years of age have not yet been published [35].

In summary, it seems reasonable for elderly patients with $\mathrm{AF}$, who require PCI, to administer acetylsalicylic acid periprocedurally followed by OAC plus clopidogrel. OAC can principally mean NOAC, but limitations apply to the currently published studies with dabigatran (more ischaemic events in lower dose, only lower dose for elderly patients) and rivaroxaban (excluding patients with higher stroke risk, dose reduction without proven clinical efficacy). Data for apixaban and edoxaban do suggest that full-dose NOAC instead of VKA is safe and efficient; however, final conclusions about the duration of acetylsalicylic acid co-medication for the elderly cannot be given at the moment similar to the unresolved status of that matter in the overall population. Current ESC recommendations emphasise that if NOACs are used, they should be given without empiric dose reduction [36]. The advantages of all combinations of NOAC and clopidogrel are significantly lower bleeding rates compared with conventional triple therapy using VKA. Another important contribution to prophylaxis of bleeding especially for elderly patients is to avoid permanent combinations of platelet inhibitors with $(\mathrm{N}) \mathrm{OAC}$ for coronary artery disease and
AF following the usual duration of DAPT or additive $\mathrm{P}^{2} \mathrm{Y}_{12}$ inhibition $[1,36]$.

\section{Conclusion}

A frequent challenge for therapeutic strategies in elderly patients is their under-representation in clinical trials; thus, trial results cannot be universally extrapolated to patients $\geq 75$ years of age. In general, elderly patients with $\mathrm{AF}$ profit from OAC compared with acetylsalicylic acid. Due to the increasing bleeding risk, acetylsalicylic acid monotherapy is no alternative for stroke prevention in $\mathrm{AF}$ in the elderly. OAC should be used based on the better efficacy at similar bleeding risk. In the four approval trials for NOACs in stroke prevention in $\mathrm{AF}$, the percentage of patients $\geq 75$ years of age ranged from 30 to $44 \%$, which allows to assess this subgroup regarding their embolic and bleeding risk. Analysing the elderly subgroups of the NOAC trials demonstrates that these patients are actually not harmed by NOACs, but that there are two tested strategies which even show an additional clinical net benefit for apixaban or edoxaban. If elderly patients do meet the predefined dose reduction criteria for apixaban or edoxaban, they have lower embolic and bleeding risks compared with VKA. If they do not meet the predefined dose reduction criteria for apixaban or edoxaban, they still have a clinical net benefit compared with VKA on the higher dose of apixaban. If combined antithrombotic therapy is required after PCI, acetylsalicylic acid should only be given peri-procedurally, and until further studies become available, the NOAC dose approved for stroke prevention in AF should be used without empiric dose reduction in most patients; however, individual decisions have to be made in the very old. At the moment, the full effective doses of apixaban and edoxaban have shown at least a similar safety profile regarding bleeding compared with VKA.

Acknowledgements Open Access funding provided by Projekt DEAL.

\section{Compliance with Ethical Standards}

Conflict of Interest AS and JB have received lecture fees and honoraria from Bayer, Boehringer Ingelheim, Bristol Myers Squibb, DaiichiSankyo, and Pfizer. UF and DB declare that they have no conflict of interest.

Open Access This article is licensed under a Creative Commons Attribution 4.0 International License, which permits use, sharing, adaptation, distribution and reproduction in any medium or format, as long as you give appropriate credit to the original author(s) and the source, provide a link to the Creative Commons licence, and indicate if changes were made. The images or other third party material in this article are included in the article's Creative Commons licence, unless indicated otherwise in a credit line to the material. If material is not included in the article's Creative Commons licence and your intended use is not permitted by statutory regulation or exceeds the permitted use, you will need to obtain permission directly from the copyright holder. To view a copy of this licence, visit http://creativecommons.org/licenses/by/4.0/. 


\section{References}

1. Kirchhof P, Benussi S, Kotecha D, Ahlsson A, Atar D, Casadei B, et al. $2016 \mathrm{ESC}$ guidelines for the management of atrial fibrillation developed in collaboration with EACTS. Eur Heart J. 2016;37(38): 2893-962. https://doi.org/10.1093/eurheartj/ehw210.

2. January CT, Wann LS, Calkins H, Chen LY, Cigarroa JE, Cleveland JC Jr, et al. 2019 AHA/ACC/HRS focused update of the 2014 AHA/ACC/HRS guideline for the management of patients with atrial fibrillation: a report of the American College of Cardiology/ American Heart Association task force on clinical practice guidelines and the Heart Rhythm Society in collaboration with the Society of Thoracic Surgeons. Circulation. 2019;140(2):e125e51. https://doi.org/10.1161/CIR.0000000000000665.

3. Steffel J, Verhamme P, Potpara TS, Albaladejo P, Antz M, Desteghe L, et al. The 2018 European Heart Rhythm Association Practical Guide on the use of non-vitamin K antagonist oral anticoagulants in patients with atrial fibrillation. Eur Heart J. 2018;39(16):1330-93. https://doi.org/10.1093/eurheartj/ehy136.

4. Sharma M, Cornelius VR, Patel JP, Davies JG, Molokhia M. Efficacy and harms of direct oral anticoagulants in the elderly for stroke prevention in atrial fibrillation and secondary prevention of venous thromboembolism: systematic review and meta-analysis. Circulation. 2015;132(3):194-204. https://doi.org/10.1161/ CIRCULATIONAHA.114.013267.

5. Lip GY, Nieuwlaat R, Pisters R, Lane DA, Crijns HJ. Refining clinical risk stratification for predicting stroke and thromboembolism in atrial fibrillation using a novel risk factor-based approach: the euro heart survey on atrial fibrillation. Chest. 2010;137(2):263-72.

6. Gage BF, Waterman AD, Shannon W, Boechler M, Rich MW, Radford MJ. Validation of clinical classification schemes for predicting stroke: results from the National Registry of atrial fibrillation. JAMA. 2001;285(22):2864-70.

7. Patti G, Cavallari I, Hanon O, De Caterina R. The safety and efficacy of non-vitamin $\mathrm{K}$ antagonist oral anticoagulants in atrial fibrillation in the elderly. Int J Cardiol. 2018;265:118-24. https://doi.org/ 10.1016/j.ijcard.2018.02.066.

8. ASCEND study collaborative group, Bowman L, Mafham M, Wallendszus K, Stevens W, Buck G, et al. Effects of aspirin for primary prevention in persons with diabetes mellitus. N Engl $\mathrm{J}$ Med. 2018;379(16):1529-39. https://doi.org/10.1056/ NEJMoa1804988.

9. McNeil JJ, Nelson MR, Woods RL, Lockery JE, Wolfe R, Reid $\mathrm{CM}$, et al. Effect of aspirin on all-cause mortality in the healthy elderly. N Engl J Med. 2018;379(16):1519-28. https://doi.org/10. 1056/NEJMoa1803955.

10. Li L, Geraghty OC, Mehta Z, Rothwell PM, Oxford Vascular S. Age-specific risks, severity, time course, and outcome of bleeding on long-term antiplatelet treatment after vascular events: a population-based cohort study. Lancet. 2017;390(10093):490-9. https://doi.org/10.1016/S0140-6736(17)30770-5.

11. Diener HC, Sacco RL, Easton JD, Granger CB, Bernstein RA, Uchiyama S, et al. Dabigatran for prevention of stroke after embolic stroke of undetermined source. N Engl J Med. 2019;380(20):190617. https://doi.org/10.1056/NEJMoa1813959.

12. Mant J, Hobbs FD, Fletcher K, Roalfe A, Fitzmaurice D, Lip GY, et al. Warfarin versus aspirin for stroke prevention in an elderly community population with atrial fibrillation (the Birmingham Atrial Fibrillation Treatment of the Aged Study, BAFTA): a randomised controlled trial. Lancet. 2007;370(9586):493-503. https://doi.org/10.1016/S0140-6736(07)61233-1.

13. Ng KH, Shestakovska O, Connolly SJ, Eikelboom JW, Avezum A, Diaz R, et al. Efficacy and safety of apixaban compared with aspirin in the elderly: a subgroup analysis from the AVERROES trial. Age Ageing. 2016;45(1):77-83. https://doi.org/10.1093/ageing/afv156.
14. Giugliano RP, Ruff CT, Braunwald E, Murphy SA, Wiviott SD, Halperin JL, et al. Edoxaban versus warfarin in patients with atrial fibrillation. N Engl J Med. 2013;369(22):2093-104. https://doi.org/ 10.1056/NEJMoa1310907.

15. Connolly SJ, Ezekowitz MD, Yusuf S, Eikelboom J, Oldgren J, Parekh A, et al. Dabigatran versus warfarin in patients with atrial fibrillation. N Engl J Med. 2009;361(12):1139-51.

16. Patel MR, Mahaffey KW, Garg J, Pan G, Singer DE, Hacke W, et al. Rivaroxaban versus warfarin in nonvalvular atrial fibrillation. $\mathrm{N}$ Engl J Med. 2011;365(10):883-91.

17. Granger CB, Alexander JH, McMurray JJ, Lopes RD, Hylek EM, Hanna M, et al. Apixaban versus warfarin in patients with atrial fibrillation. N Engl J Med. 2011;365(11):981-92.

18. Singer DE, Chang Y, Fang MC, Borowsky LH, Pomernacki NK, Udaltsova $\mathrm{N}$, et al. The net clinical benefit of warfarin anticoagulation in atrial fibrillation. Ann Intern Med. 2009;151(5): 297-305.

19. Schäfer A, Flierl U, Bauersachs J. Anti-thrombotic strategies in elderly patients receiving platelet inhibitors. Eur Heart J Cardiovasc Pharmacother. 2020;6:57-68.

20. Eikelboom JW, Wallentin L, Connolly SJ, Ezekowitz M, Healey JS, Oldgren J, et al. Risk of bleeding with 2 doses of dabigatran compared with warfarin in older and younger patients with atrial fibrillation: an analysis of the randomized evaluation of long-term anticoagulant therapy (RE-LY) trial. Circulation. 2011;123(21):236372.

21. Halperin JL, Hankey GJ, Wojdyla DM, Piccini JP, Lokhnygina Y, Patel MR, et al. Efficacy and safety of rivaroxaban compared with warfarin among elderly patients with nonvalvular atrial fibrillation in the rivaroxaban once daily, oral, direct factor Xa inhibition compared with vitamin $\mathrm{K}$ antagonism for prevention of stroke and embolism trial in atrial fibrillation (ROCKET AF). Circulation. 2014;130(2): 138-46. https://doi.org/10.1161/CIRCULATIONAHA.113.005008.

22. Halvorsen S, Atar D, Yang H, De Caterina R, Erol C, Garcia D, et al. Efficacy and safety of apixaban compared with warfarin according to age for stroke prevention in atrial fibrillation: observations from the ARISTOTLE trial. Eur Heart J. 2014;35(28):1864 72. https://doi.org/10.1093/eurheartj/ehu046.

23. Kato ET, Giugliano RP, Ruff CT, Koretsune Y, Yamashita T, Kiss RG, et al. Efficacy and safety of edoxaban in elderly patients with atrial fibrillation in the ENGAGE AF-TIMI 48 trial. J Am Heart Assoc. 2016;5(5). https://doi.org/10.1161/JAHA.116.003432.

24. Ruff CT, Giugliano RP, Braunwald E, Hoffman EB, Deenadayalu $\mathrm{N}$, Ezekowitz MD, et al. Comparison of the efficacy and safety of new oral anticoagulants with warfarin in patients with atrial fibrillation: a meta-analysis of randomised trials. Lancet. 2014;383(9921):955-62. https://doi.org/10.1016/S0140-6736(13) 62343-0.

25. G-BA Nutzendossier Modul 4B Apixaban. 2012. https://www.gba.de/downloads/92-975-212/2012-12-14 Modul4B Apixaban. pdf. Accessed 25th June 2018.

26. Alexander JH, Lopes RD, Thomas L, Alings M, Atar D, Aylward P, et al. Apixaban vs. warfarin with concomitant aspirin in patients with atrial fibrillation: insights from the ARISTOTLE trial. Eur Heart J. 2014;35(4):224-32. https://doi.org/10.1093/eurheartj/ eht 445 .

27. Lip GYH, Keshishian A, Li X, Hamilton M, Masseria C, Gupta K, et al. Effectiveness and safety of oral anticoagulants among nonvalvular atrial fibrillation patients. Stroke. 2018;49(12):293344. https://doi.org/10.1161/STROKEAHA.118.020232.

28. Hohnloser SH, Basic E, Hohmann C, Nabauer M. Effectiveness and safety of non-vitamin $\mathrm{K}$ oral anticoagulants in comparison to phenprocoumon: data from 61,000 patients with atrial fibrillation. Thromb Haemost. 2018;118(3):526-38. https://doi.org/10.1160/ TH17-10-0733. 
29. Moayyedi P, Eikelboom JW, Bosch J, Connolly SJ, Dyal L, Shestakovska O, et al. Pantoprazole to prevent gastroduodenal events in patients receiving rivaroxaban and/or aspirin in a randomized, double-blind, placebo-controlled trial. Gastroenterology. 2019;157:403-412.e5. https://doi.org/10.1053/j.gastro.2019.04. 041.

30. Hansen ML, Sorensen R, Clausen MT, Fog-Petersen ML, Raunso J, Gadsboll N, et al. Risk of bleeding with single, dual, or triple therapy with warfarin, aspirin, and clopidogrel in patients with atrial fibrillation. Arch Intern Med. 2010;170(16):1433-41. https://doi. org/10.1001/archinternmed.2010.271.

31. Dewilde WJ, Oirbans T, Verheugt FW, Kelder JC, De Smet BJ, Herrman JP, et al. Use of clopidogrel with or without aspirin in patients taking oral anticoagulant therapy and undergoing percutaneous coronary intervention: an open-label, randomised, controlled trial. Lancet. 2013;381(9872):1107-15. https://doi.org/10.1016/ S0140-6736(12)62177-1.

32. Gibson CM, Mehran R, Bode C, Halperin J, Verheugt FW, Wildgoose $\mathrm{P}$, et al. Prevention of bleeding in patients with atrial fibrillation undergoing PCI. N Engl J Med. 2016;375(25):2423-34. https://doi.org/10.1056/NEJMoa1611594.

33. Cannon CP, Bhatt DL, Oldgren J, Lip GYH, Ellis SG, Kimura T, et al. Dual antithrombotic therapy with dabigatran after PCI in atrial fibrillation. N Engl J Med. 2017;377:1513-24. https://doi.org/10. 1056/NEJMoa1708454.

34. Lopes RD, Heizer G, Aronson R, Vora AN, Massaro T, Mehran R, et al. Antithrombotic therapy after acute coronary syndrome or PCI in atrial fibrillation. N Engl J Med. 2019;380:1509-24. https://doi. org/10.1056/NEJMoa1817083.

35. Vranckx P, Valgimigli M, Eckardt L, Tijssen J, Lewalter T, Gargiulo $\mathrm{G}$, et al. Edoxaban-based versus vitamin $\mathrm{K}$ antagonist-based antithrombotic regimen after successful coronary stenting in patients with atrial fibrillation (ENTRUST-AF PCI): a randomised, open-label, phase 3b trial. Lancet. 2019;394:1335-43. https://doi. org/10.1016/S0140-6736(19)31872-0.

36. Valgimigli M, Bueno H, Byrne RA, Collet J-P, Costa F, Jeppsson A, et al. 2017 ESC focused update on dual antiplatelet therapy in coronary artery disease developed in collaboration with EACTS. Eur Heart J. 2018;39:213-60. https://doi.org/10.1093/eurheartj/ ehx419.

37. Chesebro JH, Knatterud G, Roberts R, Borer J, Cohen LS, Dalen J, et al. Thrombolysis in myocardial infarction (TIMI) trial, phase I: a comparison between intravenous tissue plasminogen activator and intravenous streptokinase. Clinical findings through hospital discharge. Circulation. 1987;76(1):142-54.

38. Schulman S, Kearon C. Subcommittee on control of anticoagulation of the $\mathrm{S}$, standardization Committee of the International Society on T, haemostasis. Definition of major bleeding in clinical investigations of antihemostatic medicinal products in non-surgical patients. J Thromb Haemost. 2005;3(4):692-4. https://doi.org/10.1111/j.1538-7836.2005.01204.x.

39. Kaatz S, Ahmad D, Spyropoulos AC, Schulman S. Subcommittee on control of A. Definition of clinically relevant non-major bleeding in studies of anticoagulants in atrial fibrillation and venous thromboembolic disease in non-surgical patients: communication from the SSC of the ISTH. J Thromb Haemost. 2015;13(11): 2119-26.

Publisher's Note Springer Nature remains neutral with regard to jurisdictional claims in published maps and institutional affiliations. 